\title{
Importance of predation and germination on loss- es from the seed bank of calden (Prosopis calde- nia)
}

\author{
PAMELA LERNER AND RAUL PEINETTI
}

\begin{abstract}
Authors are assistant professor, Facultad de Ciencias Exactas y Naturales, Universidad Nacional de La Pampa, Uruguay 151 Santa Rosa (6300) Argentina, and Facultad de Agronomía Universidad Nacional de La Pampa, cc 300Santa Rosa (6300)-Argentina.
\end{abstract}

\begin{abstract}
Calden (Prosopis caldenia) seeds not dispersed by animals sometimes constitute a considerable number of seeds to the seed bank which may contribute to the species' dissemination. The monthly change in the number of viable non-animal dispersed seeds was evaluated over a one-year period. We determined the percentage germination of seeds and the amount of predation by bruchid beetles to learn how these factors influence seed longevity. Forty eight bags containing 10 fruits were placed in 4 sites below calden tree canopies at the time of shedding (March). To monitor seed losses we randomly removed 1 bag per site every 25-35 days during a year. At the time of shedding, fruits contained 29 seeds, $73 \pm 5.0 \%$ which were viable and $9 \pm 2.2 \%$ attacked by bruchids. Viability decreased to $33 \pm 22.3 \%$ one year later. Loss of viability was described by a polynomial quadratic $\left(y=70.12+0.0238 t-0.0004 t^{2}\left(r^{2}=0.62\right)\right)$. Bags with germinated seeds were observed beginning in November. Percentage germinated seed increased $4.8 \pm 3.7 \%$ in the last month of sampling. Consumption of seeds by bruchids also increased in November, but the effect was highly variable. In the last month of sampling (March in the following year), $35 \pm 18.0 \%$ of seeds were affected by bruchids. A predictive seed longevity model was developed considering climatic variables, but data were well described only until January $\left(y=81.50-0.097\right.$ time-3.94 precipitation $\left(r^{2}=\right.$ $0.60)$ ). Undispersed seeds had a high rate of decay and low germination. Longevity was strongly affected by bruchid attack.
\end{abstract}

Key Words: seed Iongevity, bruchid beetles, seed predation, seed viability, experimental seed bank.

Calden (Prosopis caldenia) is the primary woody plant in the xerophytic savanna woodland in central Argentina. From its pod and seed characteristics the species seems to be adapted for animal dispersal. The indehiscent fruit of $P$. caldenia is formed by a colored exocarp, a spongy mesocarp that usually is sweet and nutritious, and a hard endocarp. At maturity seeds have a hard coat that delays germination, moreover they remain inside the

Authors thank N. Winzer and R. Camina for their statistical analysis assistence; C Cabeza, L. Branch and A. Kin for their assistence and critical review of a draft of the manuscript.

Manuscript accepted 16 April 1994. cavity in the endocarp until the degradation of the endocarp. The fruit of calden is palatable to wildlife and domestic livestock; the latter have been observed to consume them in large quantities (Peinetti et al. 1992). Cattle apparently increased the dissemination of calden seeds and consequently the density of this tree species has risen in the last century (Koutche and Carmenlich 1936, INTA 1980). Unconsumed fruit also may contribute to species dissemination. Knowledge of the dynamics of unconsumed seed is important to elucidate dissemination strategies in calden.

Seed loss on the soil surface is generally due to germination, removal by predators and attack by micro-organisms (Spitters 1989). The most important seed predators, in terms of number of species and individuals, documented for the genus Prosopis are beetles in the family Brachidae (Kingsolver et al. 1977; Janzen 1969). This family includes species that are specialized on only a few genera, including Prosopis. We evaluated the relative importance of predation by bruchids and germination as a cause of loss of unconsumed seeds in the soil bank of calden. In addition, we related the rate of loss of viable seeds in the soil to climatic conditions.

\section{Materials and Methods}

Between March 1990 and March 1991 we studied the longevity of calden seeds in an open forest located at Colonia Lagos site $\left(64^{\circ} 30^{\prime} \mathrm{W}, 36^{\circ} 32^{\prime} \mathrm{S}\right)$. During the fruit shedding period, in March 1990, we collected 480 calden fruits according to the following criteria: (a) a minimum $10 \mathrm{~cm}$ length, (b) presence of seeds verified by shaking fruit, (c) no more than 2 bruchid holes. Fruit selection reduced the scope of the experiment and area of extrapolation, but also reduced experimental error due to differences in the number of seeds per fruit (including fruit with no seeds), and to large differences in bruchid infectation levels.

Ten fruits were placed in wire bags $(12 \times 20 \mathrm{~cm})$ of $1-\mathrm{mm}$ mesh; each bag contained fruits of similar shape and size. In a 1 ha area fenced to exclude cattle, we established 4 sites under different trees. Sites were on the north site of trees and under the canopy in the area of fruit shedding. We placed 12 bags at each site to monitor seed loss. Approximately every 25-35 days between March 1990 and March 1991 we randomly removed 1 
bag per site and stored the seeds at $5^{\circ} \mathrm{C}$ until they were processed. We recorded the following: 1) number of pod segments and seeds, 2) number of seeds germinated in situ, 3 ) number of viable seeds, 4) number of unviable seeds, 5) number of seeds consumed by bruchids. Seeds were separated from the pods and checked for germination. To determine viability, seeds were scarified and placed in a petri dish with distilled water. These seeds were rechecked for germination after 72 hours. Any remaining ungerminated seeds were cut and treated with 2,3,5 Triphenyltetrazolium chloride for viability testing. Seeds were visually checked for bruchids at the time of scarification and after staining. Very small larvae were not detected by this method. Seed viability, seed predation, and germinated seed were expressed as a percentage of the total pod segment per fruit.

Daily temperature and precipitation were obtained from the agricultural experimental station of the Universidad Nacional de La Pampa, $16 \mathrm{~km}$ from the study site. Climatological data were averaged for each 25-35 day sampling period. A linear multiple regression analysis was used to fit the percentage of viable seeds as a function of time (day) and weather conditions (temperature and precipitation).

\section{Results}

Fruits longer than $10 \mathrm{~cm}$ contained $29 \pm 0.6$ (mean \pm S.D.) seeds of which $72.8 \pm 5 \%$ were viable at the time of fruit shedding. Viability decreased to approximately $33 \pm 22.3 \%$ one year later. The relationship between percent of viable seeds and time (t) was not linear even after Probit transformation (Ellis and Robert, 1980). Data were best described by the following polynomial quadratic equation: $y=70.12+0.0238 \mathrm{t}-0.0004 \mathrm{t}^{2}\left(\mathrm{r}^{2}=\right.$ 0.62 ) (Fig. 1). The standard deviation increased in later sampling dates but the site effect was not significant $(p=0.59)$.

Germinated seeds were observed in periods beginning

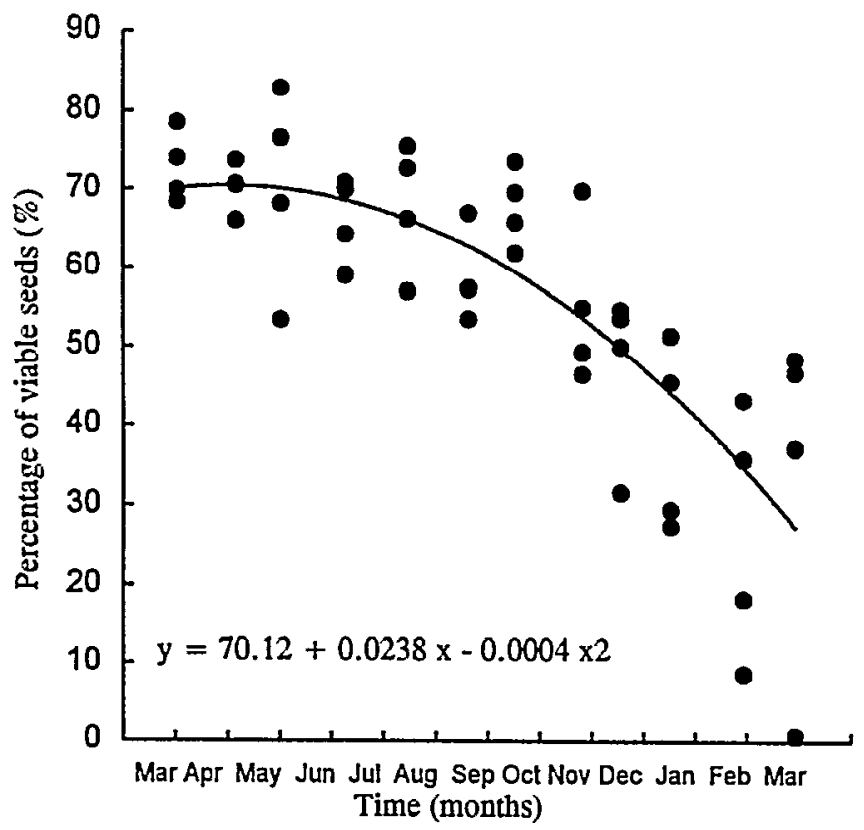

Fig. 1. Seed viability percentage during the period of sampling (each value represents a mean of 10 fruits)

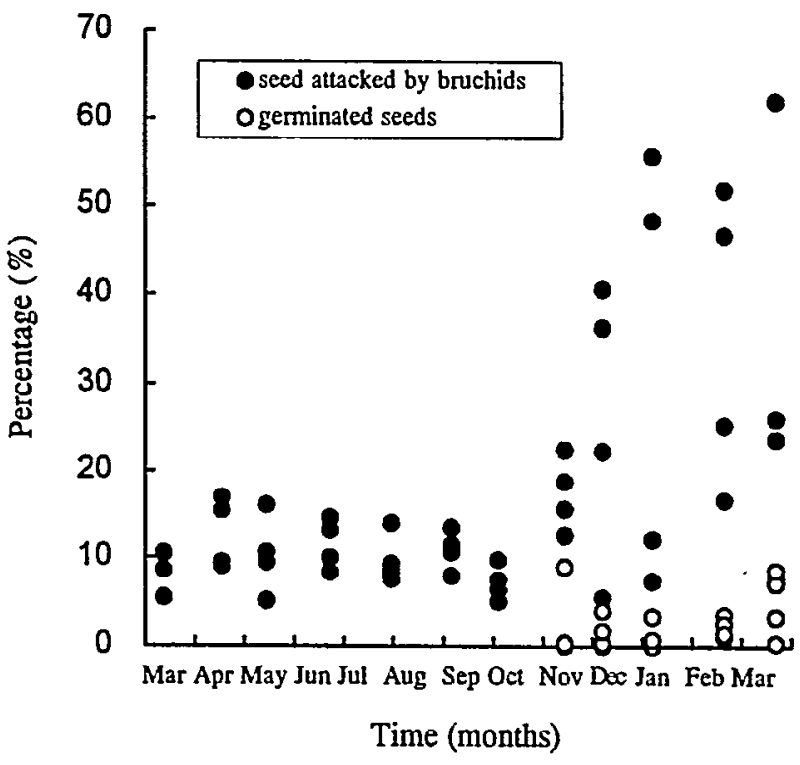

Fig. 2. Germinated seeds and seed consumed by bruchids during the period of sampling (each value represents a mean of 10 fruits).

October-November (Fig. 2). The average percentage germination for this period was $2.4 \pm 4.38 \%$. Exact dates of germination could not be determined. However the loss of seeds in the seed bank due to germination increased only $4.8 \pm 3.72 \%$ in the last month of sampling. A mean of $9.0 \pm 2.22 \%$ of the total seeds per fruit were attacked by bruchids at the time of fruit shedding. No changes in this value were observed until October-November. Beginning with this month, percentage of predated seed increased regularly to $35 \pm 18.0 \%$. However, monthly samples exhibited great variance in the degree of predation by bruchids.

Figure 3 shows mean temperature and precipitation values for

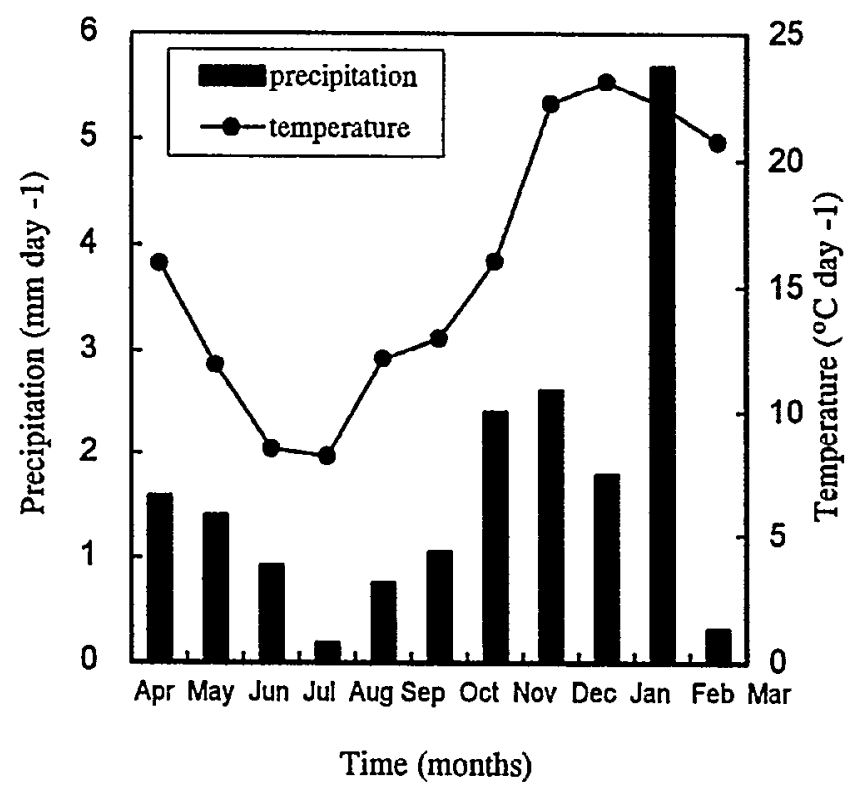

Fig. 3. Precipitation and temperature averaged for each sampling period. 
each sampling period. Both variables decreased until the late winter (August). Starting from this point variables increased (but not regularly) mainly in the case of precipitation. High rainfall occurred in October-November and January-February. In contrast, February-March had low values. A linear multiple regression applied to predict viability as a function of time and climatic factors over the whole period of sampling showed anomalous data in February-March (high residual). An adequate fit was obtained when the period of time was reduced to January-February $(\mathrm{p} \leq 0.0001)$. The regresion equations were selectionated using the stepwise regression technique (Gomez and Gomez, 1984). The model selectionated has 2 term time and precipitation $\left(\mathrm{y}=81.50-0.097 *\right.$ time-3.94 $*$ precipitation; $\mathrm{r}^{2}=$ 0.664 ) and shows a good fit considering the residuals

\section{Discussion and Conclusion}

The mean number of seeds per fruit reported by Solbrig and Cantino (1975) for 377 fruits of calden was 19.2 , with $62.3 \%$ of the seeds viable and $15.9 \%$ of seeds attacked by bruchids. The number of seeds per fruit was lower than in our study; viability was similar; and the level of infestation by bruchids was almost twice as high as in our study. It is possible that our selection of fruit overestimated the number of seeds per fruits due to sample restrictions, or a high intraspecific variability may exist in the number of seeds per fruit (Harper et al. 1970)

Linear equations for predicting seed longevity in a storage environment (Ellis and Robert 1980) do not appear to be adequate for field conditions since seed losses due to germination and predation change the potential seed longevity. If the polynomial quadratic seed longevity model were valid for a period of time longer than a year, calden seed viability in soil would be no longer than 2 years. However germination is not as important a cause of seed bank depletion as in other species (Murdoch and Ellis 1992). Probably, when environmental conditions were adequate for germination (Pelaez et al. 1992; Peinetti et al. 1993), most seeds were non-viable or non-scarified. Temperature probably inhibits calden germination during the winter. After October when the temperature has risen, moisture would be the main environmental factor determining germination. Mesquite (Prosopis glandulosa) seed temperature regulates efficient use of water for germination (Scifres and Brock 1971). Spring temperatures are high enough for germination, but moisture is usually inadequate (Tschirley and Martin 1960). Germination of 35\% in pod segments of mesquite occurred during the first summer rainy season after planting (Glendening and Paulsen 1955). Seed mortality was strongly related to bruchid activity. Development of bruchid larvae is affected by temperature. Howe and Currie (1964) found for several species of beetles that the optimum conditions for rapid development are around $30^{\circ} \mathrm{C}$ and between 70 and $80 \%$ humidity. Moreover adults emerged in a temperature range of $15^{\circ} \mathrm{C}$ to $37.5^{\circ} \mathrm{C}$. Adult weevils spend the winter either in seeds (as pupae or adult) or in litter on the ground, emerging during late spring in time for ovipositing on new green pods (Glendening and Paulsen 1955; Kingsolver 1977). On the other hand bruchids reinfest the indehiscent pods of many species of legumes in the field (Janzen 1969). In $P$. caldenia reinfection apparently occurs since October and causes a great increase in seed mortality.
The dynamics and resilience of semi-arid ecosystems, particulary savannas, can be significantly affected by herbivores, both vertebrates and invertebrates (Bucher 1987). However, explanations of plant distribution and abundance rarely consider the importance of herbivores, concentrating instead on physical factors, such as climate and soil (McNaughton 1983). Studies of seeds dispersed by animals only consider the short term effects of ingestion on seed survival and germination rate. Long term effects like changes in seed longevity have not been reported. Calden seeds not dispersed by animals persist for only a short time in the seed bank. It is not known if animal-dispersed seeds persist longer. We hypothesize that dipersal favours seed longevity. First, when seeds are dispersed by animals such as cattle or wildlife, the passage through the intestinal tract may eliminate the bruchid population and thus prevent reinfection by bruchids during spring (Miller 1993). Second, as a consequence of consumption by cattle, $P$. caldenia seeds are separated from the endocarp (Peinetti et al. 1993). Seeds may smell less attractive to the beetles in this state (Miller 1993). Janzen (1972) found that seeds naturally husked by rodents had been found to suffer $77 \%$ mortality from bruchids. Finally, dispersers carry seeds to an area where specialist seed predators are likely to be less numerous (Crawley 1983). These effects probably are more important than the increase in germination observed inmediately after consumption (Debussche 1985; Peinetti et al. 1993).

A predictive model constructed with microclimatic variables would probably have a higher regression coefficient than one produced from macroclimatic data, but the latter generally are more widely available. It is important to note that the precipitation data used in our models were means for periods approximately equal to a month. Shorter or longer periods could affect the model. Although the validity of the predictive equation should be tested with other independent data, an improved equation could be constructed taking into account variation in the bruchid infection rate at the time of fruit shedding.

\section{Literature Cited}

Bucher, E.H. 1987. Herbivory in arid and semi-arid regions of Argentina. Revista Chilena de Historia Natural 60: 265-273.

Crawley, M.J. 1983. Herbivory: The Dynamics of Animal-Plant Interactions. Univ. Calif. Press, Berkeley, Calif.

Debussche, M. 1985. Role des oiseaux disseminateurs dans la germination des graines de plantes a fruits charnus en region mediterraneenne. Oecol. Plant. 6: 365-374.

Ellis, R.H. and E.H. Roberts. 1980. Improved equations for the prediction of seed longevity. Annals of Botany 45: 13-30.

Glendening, G.E. and H.A. Paulsen. 1955. Reproduction and establishment of velvet mesquite as related to invasion of semidesert grasslands. Technical bulletin, USDA 1127: 5-50.

Gomez, K.A. and A.A. Gomez. 1984. Statistical procedures for agricultural research. John Wiley \& Sons. New York, Chichester, Brisbanc, Toronto, Singapore. pp 680.

Harper, J.L., P.H. Lovell, and K.G Moore. 1970. The shapes and sizes of seeds. Ann. Rev. Ecol. Syst. 1: 327-356.

Howe, R.W. and J.E. Currie. 1964. Some laboratory observations on the rates of development, mortality and oviposition of several species of bruchidae breeding in stored pulses. Bull. Entomol. Res. 55: 437-477.

INTA. 1980. Inventario integrado de los recursos naturales de la provincia de La Pampa. ISAG. Buenos Aires. 
Janzen, D.H. 1969. Seed-eaters versus seed size, number, toxicity and dispersal. Evolution 23: 1-27.

Janzen, D.H. 1972. Association of a rain forest palm and seed-eating beetles in Puerto Rico. Ecol. 53: 258-261.

Kingsolver, J.M., C.D. Johnson, S.R. Swier, and A.L. Teran. 1977 Prosopis fruits as a resource for invertebrates. $I n$ : Simpson B.B. (ed), Mesquite. Its Biology in two desert scrub ecosystems. Dowden, Hutchinson \& Ross, Inc., Stroudsburg. pp 108-122.

Koutche, V. and J.N.F. Carmelich. 1936. Contribucion al conocimiento de los bosques de la Republica Argentina: Estudio forestal del calden. Tomo 37. Boletin del Ministerio de Agricultura de la Nacion. Buenos Aires.

McNaughton, S.J. 1983. Compensatory plant growth as a response to herbivory. Oikos 40: 329-326.

Miller, M.F. 1993. Is it advantageous for Acacia seeds to be eaten by ungulates?. Oikos 66: 364-368.

Murdoch, A.J. and R.H. Ellis. 1992. Longevity, viability and dormancy. In: Fenner M.(ed), The ecology of regeneration in plant communities. Oxford, pp 193-229.

Peinetti, R., C. Cabeza, M. Pereyra, and O. Martinez. 1992. Observaciones preliminares sobre la diseminación del caldén (Prosopis caldenia Burk) en la región semiárida de Argentina. Turrialba, 42 (3): 415-417.
Peinetti, R., M. Pereyra, A. Kin, A. Sosa. 1993. Effects of cattle ingestion on viability and germination rate of calden (Prosopis caldenia) seeds. J. Range Manage. 46: 483-486.

Peláez, D.V., R.M. Bóo, O.M. Elia. 1992. Emergence and seedling survival of calden in the semiarid region of Argentina. J. Range Manage. 45: 564-568.

Scifres, C.J. and J.H. Brock. 1971. Thermal regulation of water uptake by germinating honey mesquite seeds. J. Range Manage. 24:157-158.

Solbrig, O.T. and P.D. Cantino. 1975. Reproductive adaptations in Prosopis (Leguminosae, Mimosoideae). J. Arnold Arborctum 56:185-210.

Spitters, C.J.T., 1989. Weeds: population dynamics, germination and competition. In: R. Rabbinge, S.A. Ward \& H.H. van Laar (eds), Simulation and Systems Management in Crop Protection. Simulation Monographs, Pudoc, Wageniningen, Vol. 32:182-392.

Tschirley, F. H. and S. Clark Martin. 1960. Germination and longevity of velvet mesquite seed in soil. J. Range Manage. 13:94-97. 